\title{
Pathya and Apathaya for seasonal and daily regimen; An Ayurveda and
}

\section{Modern perspective}

\author{
Available online at www.hjhs.co.in \\ REVIEW ARTICLE \\ Shivchandra Gurme ${ }^{a}$, Manoj Rathod ${ }^{b}$ \\ ${ }^{a}$ Associate Professor, MUPS, Ayurved College, Risod, India. \\ ${ }^{\mathrm{b}}$ Assistant Professor, Sharirkriya Department, MUPS, Ayurved College, Risod, India. \\ DOI 10.22270/hihs.v4i4.42
}

\begin{abstract}
Ayurveda the science of health suggest various theories and principles towards the achievement of healthy physical and mental status, in this regards ayurveda advocates concepts of Dinacharya (daily regimen) and Ritucharya (seasonal regimen) along with "regimen to be conducted" (Pathya) or "regimen to be avoided" (Apathaya). The considerations of Pathya (wholesome) and Apathaya (unwholesome) not only help to retain healthy status but also prevent pathogenesis of various diseases. There are certain pathological conditions that can occurs as consequences of disturbed daily and seasonal regimen such as; obesity, diabetes, constipation, diarrhea, anorexia, insomnia and asthma, etc. Considering importance of these all aspects present article summarizes role of Pathya and Apathaya with respect to modern concept of daily and seasonal regimen.
\end{abstract}

Keywords: Ayurveda, Pathya, Apathaya, Dinacharya and Ritucharya.

\section{Introduction}

Ayurveda the traditional science of healthy regimen not acts as preventive modality rather than curative means the basic principle of ayurveda help to prevent disease prevalence than their treatment. The health can be maintained through the basic principles of ayurveda i.e; Ritucharya, Dinacharya, Pathya and Apathya. Ritucharya \& Dinacharya can be described as seasonal and daily regimen respectively that offers health benefits. Pathya and Apathya means life style/ dietary regimen "to be followed" and "not to be followed" respectively for healthy living.

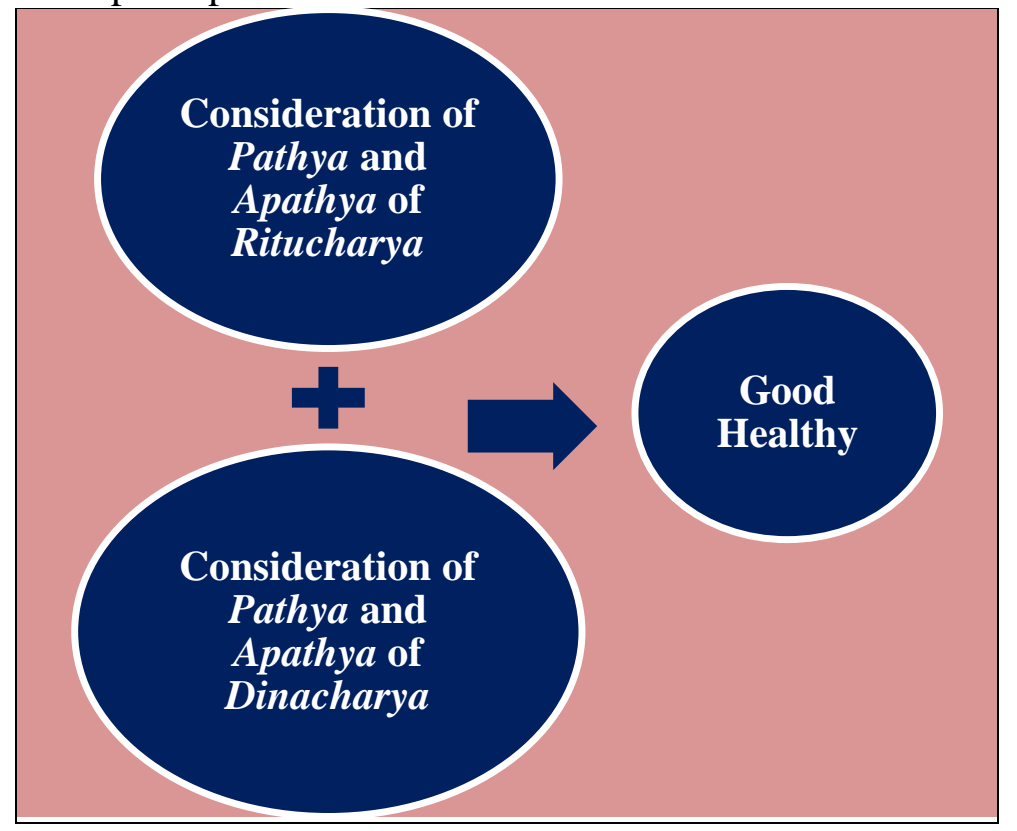

Figure 1. Considerations of rules of Ritucharya and Dinacharya for healthy well being. 
These principles of ayurveda restores normal growth and development process of body, prevent pathological triggering of many diseases, impart vitality, improves strength and provides Oja, etc. The good conduction of Ritucharya \& Dinacharya not only keep free from disease conditions but also synchronizes natural harmony amongst body, mind and soul therefore restore physical and spiritual wellbeing.

\section{Pathya and Apathya for Daily Regimen (Modern aspect)}

\section{a). Udhanam (Wake up time)}

One should wake up in early morning since fresh air that occupy in atmosphere offers several health benefits and prevent gastric problem such as; constipation and anorexia. The non-polluted fresh air helps in conditions like; asthma and bronchitis.

The late night awakening and rising late in morning can lead headache, insomnia, disturbed bowel movement and lethargy.

\section{b). Shodhna (Cleaning of body)}

Cleaning body is another important aspect of daily regimen that eliminates toxic wastes from body; maintain normal hygienic condition, keep away from infections and imparts vitality. Dantha dhavanam, Jihwa nirlekhanam and Mukha dhavanam are major way of Shodhna as daily routine. These procedures keep mouth fresh, strengthen teeth, prevent toothache and restrict pathogenesis of tonsillitis, etc.

Avoidance of daily bathing can lead infections, fever, dull personal appearance, loss of vitality and unhygienic adversity.

\section{c). Nasya (Nasal cleaning)}

Nasya means cleaning of nasal pathway that improve air circulation thus help in acute bronchitis, allergy, frequent sneezing and nasal blockage. The gentle cleaning of nostril recommended whenever one comes from polluted environmental conditions.

\section{d). Dhyana (Meditation)}

Dhyana means meditation or activities towards spiritual power; it improves mental stability, suppresses anxiety, reduces stress, pacifies depression and imparts spiritual belief.
Dhyana (meditation) is very important aspect in current scenario when stressful conditions affecting mental health of global population.

\section{e). Yoga (Exercise)}

Yoga or exercise clears body channels, increases circulation, enhances muscular strength, boosts appetite and control metabolic activities thus help in conditions like; obesity and diabetes, etc.

\section{Pathya and Apathya for seasonal} variation; Ritucharya (Modern aspect)

\section{a). Cold and dewy season (Sishira Ritu); Mid- January to Mid-March}

Sweet, sour, hot and salty food advocated in cold season. The fatty or portentous diet can be consumed due to the prompt digestive activity in this season. The need of energy and nutrition can be satisfied by taking sweet and nutritious foods.

During this season catabolism (Agni) increases but mucous (Shleshma) aggravated therefore tarty (Amla) taste food recommended to combat (Kapha Dosha).

Oil massage and exposure to sunlight also recommended preventing adverse effects of cold environmental conditions.

\section{b). Spring season (Vasanta); Mid- March to Mid-May}

The digestible foods advocated in spring season due to the diminished appetite than winter season. The astringent predominance of this season keeps appetite in moderate state thus easily digestible and bitter foods such as; wheat, rice, cereals, barley and vegetables can be used in this season. Bathing, exercise and massage suggested.

Sour, fatty, heavy and sweet food stuffs not recommended in this season since these food can increases mucous secretion leading to the disease conditions. Cold, heavy and viscous food need to be avoided. The consumption of such incompatible foods can lead pathological conditions like; constipation, allergy and dehydration.

c). Summer season (Grishma); Mid- May to Mid-July 
The hot environmental condition diminishes strength and appetite (Agni) becomes low thus sweet, unctuous, cool and fluid properties of food recommended. Light, sweet, liquid and energy rich food stuffs; rice, curd, buttermilk, meat soups, cornflour, fruits and juices are recommended in this season.

One should remain in cool place, use of aromatic materials, wearing light dresses and day time napping recommended.

The bowel activity or digestive strength decreases therefore acidic, sour, heavy and spicy foods should not be consumed. The consumption of incompatible food may lead dysentery, diarrhea, dehydration and muscular fatigue.

Excessive exercise and sexual activities are to be avoided. Exposure to sunlight avoided to prevent sun burn and dehydration.

\section{d). Rainy season (Varsha); Mid- July to Mid- September}

During this time strength becomes weak (Vata Dosha), digestive fire gets vitiated and susceptibility to infections increases therefore tarty, salty and unctuous foods such as; old barley, grains, rice, wheat and soup, etc. recommended.

Unhygienic food, street food \& junk foods need to be avoided in this season since chances of infections are more due to the diversified environmental conditions. Diarrhea, allergy and common fever, etc. are prevalent in rainy season due to the consumption of incompatible foods.

Drenching in rain, excessive sexual indulgence, hard work and bathing with cold water are to be avoided.

\section{e). Autumn/ Fall season (Sharat Ritu); Mid- September to Mid- November}

The prevalent taste is salty (Lavana), strength remains in medium state and bowel movement increases therefore sweet (Madhura) and light (Laghu) food stuffs recommended.

Bitter, sweet and astringent food stuffs such as; wheat, rice, honey, green gram, sugar and vegetables can be recommended in this season.
The diminish strength of appetite (aggravated Pita) restrict consumption of heavy and oily food stuffs.

Day time napping, exposure to sun light and overeating should be avoided during this time to prevent health adversity.

\section{f). Late Autumn (Hemant Ritu); Mid- November to Mid- January}

Sweet, salty and sour foods such as; sugarcane, grains, wheat and milk should be consume in this season since this time environmental conditions are cold and sweet taste (Madhura) is predominant. The strength remain on high state and appetite (Agni) increases therefore green gram, Masha, fats, milk and sesame, etc. can be consumed.

Exercise, body massage, bathing with warm water and sunbath recommended getting health benefits of this season.

Day time napping, exposure to cold, consumption of cool and dry foods items should be avoided in this season.

\section{Conclusion}

Pathya is one of the important terms that elaborated as good conduction of dietary and living regimen in all times to maintain normal physiological functioning of body. The good conduction of daily regimen corrects irregularities that may occur due to the ageing or environmental diversity. Pathya soften channels of circulation thus detoxify body and prevent common illness related to the toxic accumulation. The good conduction of daily and seasonal regimen nourishes body, boosts mental strength, prevents diseases and restores overall health status including physical as well as spiritual well-being. It is stated that conduction of Pathya Aahar-Vihara help to keep away from diseases and one may not require medicine for his/her life span. The consideration of basic principles of Pathya and Apathya with respect to seasonal conduct (Ritucharya) and daily regimen (Dinacharya) offers several health benefits that provide healthy well-being.

\section{Acknowledgements}


I would like to express my gratitude to Himalayan Journal of Health Sciences who gave me the opportunity to publish the article.

Financial Disclosure statement: The author received no specific funding for this work.

\section{Conflict of Interest}

The author declares that there is no conflict of interest regarding the publication of this article.

\section{References}

1. Agnivesh, Arthedashamahaamuliya Adhyaay, Sutra Sthan, Charak Samhita with Chakrapani Teeka,ed. Yadavji Trikam Ji, Ist edition, Chaukhambha Surbharti Prakashan, Varanasi, 2014, page- 187.

2. Sushrut, Annapaan Vidhi Adhyay, Sushrut Samhita with Nibandh Sangrah \& Nyay Chandrika Commentary, translator Keval Krishna Thakral, Ist edition, Vol. I, Chaukhambha Orientalia, Varanasi, 2014, page- 544.

3. Kashyap, Amlapitta Chikitsaadhyay, editor Prof. P.V.Tiwari, Kashyap Samhita, 1st edition, Varansi, Chaukhamba Vishvabharti, 1996, page- 468.
4. Bhel, Atyashitiya Adhyay, Bhel Samhita, editor Abhay Katyayan, Chaukhambha Surbharti, Prakashan, Varanasi, 2009, page- 15.

5. Sharangdhar, Kwath Kalpana Adhyay, Madhyam Khand, Sharangdhar Samhita with Dipika and Gudaartha Dipika Commentary, editor Vidyasagar Pandit Parshuram Shashtri, Chaukhambha Surbharti Prakashan, Varanasi, 2013, page- 164-170.

6. Bhavprakash, Haritakyadi Varga, Bhavprakash Nighantu, commentary by K.C. Chunekar, Varansi, Chaukhambha Bharti Academy, 2013, page- 14.

7. Priyanka Sharma, Mangalagowri Rao, Ushapana: A Unique Contribution of Ayurveda for Maintenance of Health, World Journal of Pharmaceutical Research, 2014; 3(10): 299.

8. http://www.indiadivine.org/content/topic/-1393542monier-williams-sanskrit-english.

9. Suresh Babu and M. Madhavi; Geriatrics in Ayurveda, 1st Edition, Varanasi, Chaukhambha Orientalia, 2001, 11

10. Shanker Lal Burdak, Nisha Gupta, A Review of Preventive Health Care in Geriatrics through Ayurveda, International Journal of Ayurvedic Medicine, 2015; 6 (2): 100-112. 